\title{
Glutathione peroxidase and malondialdehyde in children with chronic hepatitis $C$
}

\author{
Mohammed Ahmed Khedr', Hanaa Ahmed El-Araby ${ }^{1}$, Hatem Abdel-Sattar Konsowa', Samia Salem Sokar², \\ Mohammed Fathy Mahmoud' ${ }^{1}$ Nermin Mohammed Adawy' ${ }^{1}$, Haidy Mohammed Zakaria ${ }^{3}$ \\ 'Department of Pediatric Hepatology, Gastroenterology and Nutrition, National Liver Institute, Menoufia University, Shebin El-koom, \\ Menoufia, Egypt \\ 2Pharmacology and Toxicology Department, Faculty of Pharmacy, Tanta University, Egypt \\ ${ }^{3}$ Pediatric Department, Quesna Central Hospital, Ministry of Health, Menoufia, Egypt
}

\begin{abstract}
Aim of the study: We aimed to assess oxidative stress factors, glutathione peroxidase (GPX) and malondialdehyde (MDA) in children with chronic hepatitis $\mathrm{C}(\mathrm{CHC})$ and their relation to treatment response.

Material and methods: The study included 50 children with chronic hepatitis C virus (HCV) before treatment (naïve HCV), 25 children responders to HCV treatment, 25 children non-responders to HCV treatment and 25 healthy controls. All patients and controls were subjected to GPX and MDA measurement by enzyme-linked immunosorbent assay.

Results: The average GPX activity in erythrocytes of naïve CHC patients was $29.2 \pm 10.3 \mathrm{mU} / \mathrm{ml}$. It was statistically significantly lower than the average activity of GPX in erythrocytes of the healthy control group ( $47.3 \pm 5.2 \mathrm{mU} / \mathrm{ml}$ ) $(p<0.05)$. The average GPX activity in erythrocytes of the responder group was $34.93 \pm 3.17 \mathrm{mU} / \mathrm{ml}$. It was statistically significantly higher than the average activity of GPX in erythrocytes of the non-responder group $(11.7 \pm 4.2 \mathrm{mU} / \mathrm{ml})$ $(p<0.05)$. Plasma MDA was significantly higher in naïve CHC patients than in healthy controls $(9.7 \pm 3.7 \mathrm{nmol} / \mathrm{ml}$ vs. $3 \pm 1.1 \mathrm{nmol} / \mathrm{ml}, p<0.0001)$. Furthermore, plasma MDA concentration was significantly decreased in the responder group ( $5.36 \pm 0.7 \mathrm{nmol} / \mathrm{ml}$ ) and elevated in the non-responder group $(16.05 \pm 2.9 \mathrm{nmol} / \mathrm{ml})$.

Conclusions: Lower pretreatment levels of GPX and higher MDA level might be markers of oxidative stress occurring in $\mathrm{HCV}$ patients. Reversal of changes of these levels with completion of the treatment may indicate a correlation between oxidative stress and the viral pathogenesis.
\end{abstract}

Key words: malondialdehyde, glutathione peroxidase, hepatitis C virus.

\section{Address for correspondence}

Haidy Mohammed Zakaria, MD, Pediatric Department, Quesna Central Hospital, Ministry of Health, Menoufia, Egypt, phone: +20 1005768306, e-mail: drhaydi2000@gmail.com

\section{Introduction}

Hepatitis $\mathrm{C}$ virus (HCV) infection affects about 3\% of the world population. Egypt has a high prevalence of $\mathrm{HCV}$, especially genotype $4 \mathrm{a}$. HCV is a leading cause of hepatocellular carcinoma (HCC) and chronic liver disease [1]. The United States (US) Food and Drug Administration on April 2017 approved supplemental applications for Sovaldi (sofosbuvir) and Harvoni (ledipasvir and sofosbuvir) to treat HCV in children of ages 12 to 17 years or weighing at least 35 kilograms without cirrhosis or with mild cirrhosis. However, in children below 12 years, interferon $a$ (IFN- $\alpha$ )-based therapies and ribavirin are still the standard of care therapy [2].

Different mechanisms including immunological liver damage, direct cytotoxicity mediated by different viral products and induction of oxidative stress (OS) have been suggested as playing a pathogenic role in this infection. It has been suggested that HCV may cause OS in infected cells [3].

Moreover, it has been shown that patients with chronic hepatitis $\mathrm{C}$ (CHC) exhibit increased production of tumor necrosis factor a (TNF- $\alpha$ ), a cytokine that can produce OS by simulating the generation of 
reactive oxygen species (ROS) such as superoxide ion $\left(\mathrm{O}_{2}\right)$ and hydrogen peroxide $\left(\mathrm{H}_{2} \mathrm{O}_{2}\right)$. ROS can damage cells by causing lipid peroxidation, and oxidative damage of DNA and proteins, and by depleting ATP stores. In the presence of metals (such as $\mathrm{Fe}^{3+}$ ), $\mathrm{O}_{2}$ can react with $\mathrm{H}_{2} \mathrm{O}_{2}$ to generate a hydroxyl radical then become even more reactive and cytotoxic than $\mathrm{O}_{2}$ or $\mathrm{H}_{2} \mathrm{O}_{2}$ [4]. Lipid peroxidation is caused by free radicals leading to oxidative destruction of polyunsaturated fatty acids constitutive of cellular membranes and to the production of toxic and reactive aldehyde metabolites such as malondialdehyde (MDA), which is commonly used as an index of lipid peroxidation [5].

Although both HCV and hepatitis B virus (HBV) cause hepatitis, HCV appears to be particularly potent at inducing OS, suggesting there are OS-inducing mechanisms that are unique to this virus [6]. Lipid and protein oxidation occur in $\mathrm{CHC}$, oxidative damage can be demonstrated by increased serum levels of MDA, and MDA correlates with disease activity [7].

We aimed to assess the oxidative stress factors glutathione peroxidase (GPX) and MDA in children with chronic hepatitis $\mathrm{C}$ before and after combined interferon and ribavirin therapy.

\section{Material and methods}

\section{Study population}

One hundred and twenty-five individuals were enrolled in this study, 100 patients with chronic HCV infection recruited from the outpatient clinic and the inpatient department of the pediatric hepatology department, National Liver Institute, Menoufia University. They were divided into the following groups group I: 50 children with chronic HCV before treatment (naïve $\mathrm{HCV}$ ), group II: 25 children responding to HCV treatment, group III: 25 children not responding to HCV treatment and group IV: 25 control subjects matched in age and sex.

Signed informed consent was obtained from the parents of all the patients and controls before enrollment in the study. The study was approved by the Research Ethics Committee of the National Liver Institute.

\section{Treatment protocol}

Treated children received subcutaneous injections of Peg-IFN- $a-2 b\left(60 \mu \mathrm{g} / \mathrm{m}^{2} /\right.$ week $)$ combined with oral ribavirin $(15 \mathrm{mg} / \mathrm{kg} /$ day $)$. Real-time PCR for HCV-RNA was performed at the baseline (before treatment), $12^{\text {th }}, 24^{\text {th }}$ and $48^{\text {th }}$ weeks during treatment, and 24 weeks post-treatment. Complete sustained vi- rological response (SVR) was defined as normalization of serum alanine aminotransferase (ALT) and undetectable HCV-RNA during the course of treatment and persistence during the entire 6 months' post-therapy follow-up period. Non-responders were defined as HCV-RNA remains detectable and/or ALT fails to normalize throughout the treatment phase.

\section{Etiological diagnosis and group allocation}

$\mathrm{HCV}$ infection was defined by positive anti-HCV, a positive PCR for HCV-RNA, negative hepatitis B viral markers and absence of any associated liver disease, supported by the histopathological features of HCV infection in liver biopsy. To eliminate the possibility of any renal complications, kidney functions and abdominal ultrasound screening for patients were included. Patients with decompensated liver disease, cirrhosis, and impaired renal functions were all excluded from the study.

Control group subjects were defined as apparently healthy individuals with no signs or symptoms of liver disease or any other diseases, and negative anti-HCV Ab.

\section{Sample collection and laboratory investigations}

Blood samples (about $10 \mathrm{ml}$ ) were collected under complete aseptic technique from patients. Blood was allowed to clot naturally in the test tube, serum was then separated by centrifugation, divided into small aliquots and stored immediately at $-80^{\circ} \mathrm{C}$ until the time of use for liver function tests (LFTs), kidney function tests (urea and creatinine), viral markers, and HCV-RNA. A second sample was added to EDTA for complete blood count and tested immediately. A third sample was added to $\mathrm{Na}$ citrate for prothrombin time and concentration [8] and tested just before performing liver biopsy. A fourth sample was added to EDTA, and then separated by centrifugation; plasma was then separated by centrifugation and stored immediately at $-80^{\circ} \mathrm{C}$ until the time of use for MDA. $100 \mu$ of packed red cells plus $400 \mu \mathrm{l}$ of distilled water was mixed and centrifuged. Supernatant was taken and stored immediately at $-80^{\circ} \mathrm{C}$ until the time of use for GPX.

\section{Abdominal ultrasonography}

To assess the size and echo pattern of the liver, the size of the spleen, and the presence of ascites, abdominal ultrasonography was performed.

\section{Liver biopsy and histopathological evaluation}

Liver biopsy was done for patients whenever possible. Liver biopsies were performed using true cut 
needle. Biopsy specimens were fixed in formalin, embedded in paraffin, followed by a histopathological examination of the specimen using hematoxylin and eosin stains, orcein stain, Masson's trichrome, reticulin and Perl's stains and PAS (periodic acid Schiff) stain. Hepatic necroinflammatory activity and liver fibrosis were evaluated according to the Ishak staging and grading score [9]. Necroinflammatory activity was classified as mild (score 1-5), moderate (score 6-8) and severe (score 9-18). Fibrosis was classified as mild (stage 1), moderate (stages 2-3), and severe fibrosis or cirrhosis (stages 4-6) [10].

\section{Determination of malondialdehyde measurement by enzyme-linked immunosorbent assay (ELISA)}

The lipid peroxides products were estimated in plasma of chronic HCV-infected children and the control group by determination of the level of thiobarbituric acid reactive substances (TBARS) that were measured as MDA. The later is a decomposition product of the process of lipid peroxidation and is used as a measure of this process.

It depends on colorimetric determination of the pink color resulting from the reaction of TBARS with thiobarbituric acid in acidic medium, at high temperature $\left(100^{\circ} \mathrm{C}\right)$. To increase the specificity and sensitivity of the assay, the resultant color product was extracted in $\mathrm{n}$-butanol and measured at $535 \mathrm{~nm}$ to exclude interfering substances [11].

\section{Determination of glutathione peroxidase measurement by ELISA}

The assay is an indirect measure of the activity of c-GPx. Oxidized glutathione (GSSG), produced upon reduction of an organic peroxide by c-GPx, is recycled to its reduced state by the enzyme glutathione reductase (GR):

$$
\begin{gathered}
\mathrm{c}-\mathrm{GPx} \\
\mathrm{R}-\mathrm{O}-\mathrm{O}-\mathrm{H}+2 \mathrm{GSH} \rightarrow \mathrm{R}-\mathrm{O}-\mathrm{H}+\mathrm{GSSG}+\mathrm{H}_{2} \mathrm{O} \\
\text { GR } \\
\text { GSSG }+\mathrm{NADPH}+\mathrm{H}^{+} \rightarrow 2 \mathrm{GSH}+\mathrm{NADP}^{+}
\end{gathered}
$$

The oxidation of NADPH to $\mathrm{NADP}^{+}$is accompanied by a decrease in absorbance at $340 \mathrm{~nm}\left(\mathrm{~A}_{340}\right)$, providing a spectrophotometric means for monitoring GPx enzyme activity. The molar extinction coefficient for NADPH is $6220 \mathrm{M}^{-1} \mathrm{~cm}^{-1}$ at $340 \mathrm{~nm}$. To assay c-GPx, a cell or tissue homogenate is added to a solution containing glutathione, glutathione reductase, and NADPH. The enzyme reaction is initiated by adding the substrate, hydrogen peroxide and the $\mathrm{A}_{340}$ is recorded. The rate of decrease in the $\mathrm{A}_{340}$ is directly proportional to the GPx activity in the sample.

\section{Statistical analysis}

Data were analyzed using SPSS, version 18.0 (SPSS Inc., Chicago, Illinois, USA). Data were entered as numerical or categorical, as appropriate. Quantitative data were shown as median (minimum-maximum).

Qualitative data were expressed as frequency and percent at $95 \%$ confidence interval $(95 \% \mathrm{CI})$. The chisquare $\left(\chi^{2}\right)$ test was used to measure associations between qualitative variables. The Mann-Whitney $U$ test was performed to compare means and SD of 2 sets of quantitative data. The Kruskal-Wallis test was used to compare between the three groups regarding quantitative variables. The post-hoc test was used for multiple comparisons of MDA and GPX levels between multiple groups. Spearman's correlation test was used for assessing the correlation between two continuous variables. $P$-value $<0.05$ was considered statistically significant.

\section{Results}

Both naïve HCV patients and the healthy controls were age and sex matched $(p>0.05) .66 \%$ of the naïve HCV patients were male and $34 \%$ were female. Their median (minimum-maximum) age was 9 (4-12) years. The control group included $64 \%$ males and $36 \% \mathrm{fe}-$ males. Their median (minimum-maximum) age was 8.5 (5-12) years.

In the present study, we found that there was no statistically significant difference between HCV-treatment responders and non-responders regarding both the gender and the age of patients (Table 1).

On assessing the probable risk factors for acquisition of infection, we found that operations and tooth extraction were the most incriminated risk factors for acquisition of infection. On screening for the mode of presentation of $\mathrm{HCV}$ infection in our children, 92\% children were incidentally discovered, while $8 \%$ of children had a history of jaundice.

By examination of the naive HCV patients, jaundice was present in $8 \%$, hepatomegaly in $14 \%$ and splenomegaly in $6 \%$ (Table 1 ). In addition, hepatomegaly was detected by abdominal ultrasonography in $12 \%$ of patients while splenomegaly was detected by abdominal ultrasonography in $10 \%$ of patients. On assessing the laboratory parameters of the studied group, we found that the mean values of liver function tests, renal function tests, red blood cell count (RBS), complete blood count (CBC) parameters and thyroid stimulating hormone (TSH) were nearly within normal ranges (Table 1). 
Table 1. Clinical examination, laboratory parameters and histopathological finding in HCV group $(n=50)$

\begin{tabular}{|c|c|}
\hline Clinical examination & \\
\hline Weight (kg) & $29(16-42)$ \\
\hline Height (cm) & $126(95-158)$ \\
\hline BMI & $19.6(15.4-30.1)$ \\
\hline Jaundice & $4(8 \%)$ \\
\hline Hepatomegaly & $7(14 \%)$ \\
\hline Splenomegaly & $3(6 \%)$ \\
\hline Ascites & $0(0 \%)$ \\
\hline \multicolumn{2}{|l|}{ Laboratory parameters } \\
\hline Total bilirubin (mg/dl) & $0.6(0.2-1.5)$ \\
\hline Direct bilirubin (mg/dl) & $0.13(0.07-0.44)$ \\
\hline Albumin (gm/l) & $4.35(3.10-5.20)$ \\
\hline ALT (IU/I) & $43.16(10.60-301)$ \\
\hline AST (IU/I) & $41.08(6-184.7)$ \\
\hline $\mathrm{ALP}(\mathrm{IU} / \mathrm{I})$ & $199.5(29-924)$ \\
\hline GGT (IU/I) & $22(11-117)$ \\
\hline PT (s)w & $13(10.5-17)$ \\
\hline PC\% & $92(63-119)$ \\
\hline INR & $1.04(0.88-1.49)$ \\
\hline Ferritin (ng/ml) & $52(11.4-172)$ \\
\hline Urea (mg/dl) & $24(15-36)$ \\
\hline Creatinine (mg/dl) & $0.64(0.30-0.96)$ \\
\hline $\mathrm{Hb}(\mathrm{gm} / \mathrm{dl})$ & $12.8(9.80-16.50)$ \\
\hline WBCs $\times 10^{3}$ & $7(3.4-13.4)$ \\
\hline Platelets $\times 10^{3}$ & $257(125-521)$ \\
\hline Quantitative HCV PCR (IU/ml) & $84550(548-4500056)$ \\
\hline \multicolumn{2}{|l|}{ Histopathological finding } \\
\hline \multicolumn{2}{|l|}{ Stage of fibrosis } \\
\hline Mild & $34(68 \%)$ \\
\hline Moderate & $16(32 \%)$ \\
\hline Biopsy staging $(0 / 6)$ & $2(1-3)$ \\
\hline \multicolumn{2}{|l|}{ Degree of activity } \\
\hline Minimal & $22(44 \%)$ \\
\hline Mild & 27 (54\%) \\
\hline Moderate & $1(2 \%)$ \\
\hline Biopsy grading $(0 / 18)$ & $4(2-10)$ \\
\hline
\end{tabular}

$B M I$ - body mass index, ALT - alanine aminotransferase, AST - aspartate aminotransferase, ALP - alkaline phosphatase, GGT - gamma glutamyl-transferase, $P T$ - prothrombin time, $P C$ - prothrombin concentration, INR - international normalized ratio, Hb - hemoglobin, WBCS - white blood cells

On comparing the data of the treatment responders and non-responders, it was remarkable in our study that the level of ALT did not significantly affect HCV
Table 2. Comparison between clinical, ultrasonographic and radiological findings of the responders and non-responders

\begin{tabular}{|c|c|c|c|}
\hline Factor & $\begin{array}{l}\text { Responders } \\
(n=25)\end{array}$ & $\begin{array}{c}\text { Non-responders } \\
(n=25)\end{array}$ & $p$-value \\
\hline Male & $14(56 \%)$ & $19(76 \%)$ & 0.248 \\
\hline Female & $11(44 \%)$ & $6(24 \%)$ & \\
\hline Age (years) & $10(4-12)$ & $8(4-12)$ & 0.062 \\
\hline \multicolumn{4}{|l|}{ Clinical data } \\
\hline Weight (kg) & $32(15-64)$ & $26(14-55)$ & 0.165 \\
\hline Height $(\mathrm{cm})$ & $133(90-165)$ & $123(93-158)$ & 0.404 \\
\hline BMI & $19(15.8-26.4)$ & $18(14-24.4)$ & 0.158 \\
\hline Jaundice & $1(4.0 \%)$ & $6(24.0 \%)$ & $0.042^{*}$ \\
\hline Hepatomegaly & $3(12.0 \%)$ & $4(16.0 \%)$ & 1 \\
\hline Splenomegaly & $1(4.0 \%)$ & $2(8.0 \%)$ & 1 \\
\hline \multicolumn{4}{|l|}{ Ultrasonography } \\
\hline Hepatomegaly & $6(24 \%)$ & $9(36 \%)$ & 0.355 \\
\hline Liver span (cm) & $13(10-16.2)$ & $12(9.5-17)$ & 0.188 \\
\hline Splenomegaly & $2(8.0 \%)$ & $11(44 \%)$ & $0.004^{*}$ \\
\hline Splenic length (cm) & $10(7.5-13.4)$ & $9.6(7-15)$ & 0.668 \\
\hline \multicolumn{4}{|l|}{ Laboratory parameters } \\
\hline Total bilirubin (mg/dl) & $0.55(0.1-1.9)$ & $0.8(0.3-3.5)$ & $0.004^{*}$ \\
\hline Direct bilirubin (mg/dl) & $0.16(0.05-0.65)$ & $0.2(0.10-1.10)$ & 0.390 \\
\hline Albumin (g/l) & $4.2(3.20-5.20)$ & $4.1(3.10-5.10)$ & 0.376 \\
\hline ALT (IU/ml) & $43(12-203)$ & $45(24-416)$ & 0.151 \\
\hline AST (IU/ml) & $33(19-143)$ & $43(25-632)$ & $0.013^{*}$ \\
\hline $\operatorname{ALP}(\mathrm{IU} / \mathrm{ml})$ & $188(71-354)$ & $171(24.5-378)$ & 0.497 \\
\hline GGT (IU/ml) & $25.5(8-99)$ & $29(9-320)$ & 0.524 \\
\hline PT (s) & $12.9(10.9-14.5)$ & $13(12-15.7)$ & 0.170 \\
\hline PC\% & $93.3(75-103)$ & $100(62.3-100)$ & 0.864 \\
\hline INR & $1.01(0.93-1.23)$ & $1(1-1.5)$ & 0.972 \\
\hline Ferritin (ng/ml) & $67.7(11.4-324.5)$ & 76.9 (5.98-559) & 0.672 \\
\hline Urea (mg/dl) & $24(18-34)$ & $25.5(11-35)$ & 0.591 \\
\hline Creatinine (mg/dl) & $0.51(0.3-0.9)$ & $0.5(0.3-0.9)$ & 0.953 \\
\hline $\mathrm{Hb}(\mathrm{gm} / \mathrm{dl})$ & $12.3(9.8-14.7)$ & $11.9(10-14.8)$ & 0.515 \\
\hline WBCs $\times 10^{3}$ & $6.6(3.3-11.5)$ & $6.8(4-12.5)$ & 0.509 \\
\hline Platelets $\times 10^{3}$ & 258 (123-472) & 265 (149-636) & 0.548 \\
\hline HCV PCR (IU/ml) & $\begin{array}{c}164000 \\
(651-2980000)\end{array}$ & $\begin{array}{c}810000 \\
(1448-21100000)\end{array}$ & $0.033^{*}$ \\
\hline
\end{tabular}

*significant data

$B M I$ - body mass index, ALT - alanine aminotransferase, AST - aspartate aminotransferase, ALP - alkaline phosphatase, GGT - gamma glutamyl-transferase, $P T$ - prothrombin time, $P C$ - prothrombin concentration, INR - international normalized ratio, Hb - hemoglobin, WBCS - white blood cells

treatment response. In the current study, it was found that the level HCV viremia in HCV treatment nonresponders was significantly higher than responders 
$(p<0.05)$ (Table 2). In this study, there was no statistically significant difference between histopathological activity and response to therapy (Table 3 ).

In the current study, the median (minimum-maximum) GPX activity in erythrocytes of naïve CHC patients was $27.1(14.5-56.2) \mathrm{mU} / \mathrm{ml}$. It was statistically significantly lower than the activity of GPX in erythrocytes of the healthy control group, 46.63 (39.45-58.63) $\mathrm{mU} / \mathrm{ml}(p<0.05)$. The GPX activity in erythrocytes of the responder group was 35.8 (29.9-41.3) $\mathrm{mU} / \mathrm{ml}$. It was statistically significantly higher than the average activity of GPX in erythrocytes of the non-responder group, 11 (5.4-20) mU/ml $(p<0.05)$ (Fig. 1).

In this study, plasma MDA was significantly higher in naïve CHC patients than in healthy controls: 8.6 (4.1-19.7) nmol/ml vs. 3 (1-4.7) nmol/ml, $p<0.0001)$. Furthermore, plasma MDA concentration was significantly decreased in the responder group, 5.6 (3.7-6.7) $\mathrm{nmol} / \mathrm{ml}$, and elevated in the non-responder group, 15.8 (12.1-24.9) nmol/ml (Fig. 2).

In the current study, there was a negative correlation between levels of MDA and GPX in all studied groups (Fig. 1).

Lastly, there were no statistically significant correlations between MDA and GPX levels and other parameters: age, height, weight, body mass index, liver span, splenic length, LFTS, RFTS, TSH, ferritin, HCVRNA PCR, CBC, degree of activity, or stage of fibrosis $(p>0.05)$.

\section{Discussion}

Hepatitis C virus is an important global health problem that causes acute and chronic hepatitis. The virus was discovered in the USA in 1989 and about three to four million people are infected every year worldwide. Humans are the natural hosts of HCV and the virus can eventually lead to permanent liver damage and HCC [13].

Hepatitis $\mathrm{C}$ virus infection in children is different from that in adults in many aspects, such as natural course of the disease, duration of infection, therapeutic response, side effects of drug therapy and prognosis [14].

Our study showed predominance of males over females with CHC. Most of the patients with HCV infection were incidentally discovered. The significant association between operations and tooth extraction alerts us to the importance of checking on surgical tools' sterilization. In a study performed by Barakat and El-Bashir [15], they found that the most common potential risk factor for HCV infection in children was surgery (sutures, abscess draining, tonsillectomy and
Table 3. Comparison between histopathological findings of the responders and non-responders

\begin{tabular}{|c|c|c|c|}
\hline & $\begin{array}{c}\text { Responders } \\
(n=12)\end{array}$ & $\begin{array}{c}\text { Non-responders } \\
(n=16)\end{array}$ & $p$-value \\
\hline \multicolumn{4}{|l|}{ Stage of fibrosis } \\
\hline Mild & $11(91.7 \%)$ & $13(81.3 \%)$ & \multirow[t]{2}{*}{0.613} \\
\hline Moderate & $1(8.3 \%)$ & $3(18.8 \%)$ & \\
\hline Biopsy staging $(0 / 6)$ & $1(1-3)$ & $2(1-4)$ & 0.085 \\
\hline \multicolumn{4}{|l|}{ Degree of activity } \\
\hline Minimal & $4(33.3 \%)$ & $6(37.5 \%)$ & \multirow{3}{*}{0.393} \\
\hline Mild & $8(66.7 \%)$ & $8(50.0 \%)$ & \\
\hline Moderate & $0(0.0 \%)$ & $0(0.0 \%)$ & \\
\hline Biopsy grading $(0 / 18)$ & $5(3-8)$ & $5(3-10)$ & 0.849 \\
\hline
\end{tabular}

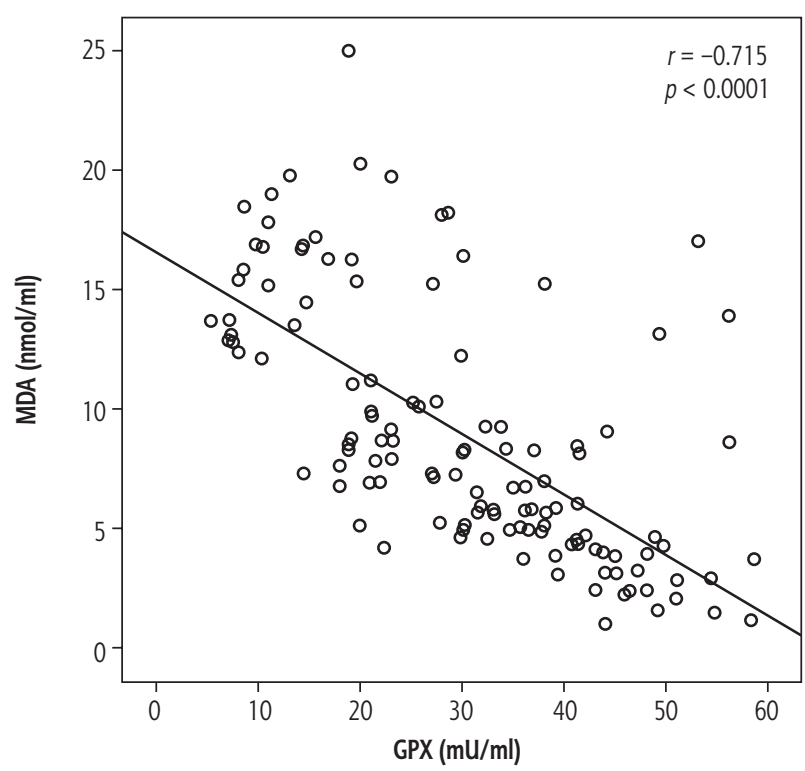

Fig. 1. Scatter plot showing the correlation between MDA and GPX, with the reference line implying a negative correlation

appendectomy), and the second highest risk factor was the use of IV catheters.

The HCV level of viremia in HCV treatment non-responders was significantly higher than responders. This finding agreed with El-Zayadi [16], who reported that the lower baseline HCV RNA level in adults is an important predictor of response to IFNbased therapy.

Patients with a high degree of fibrosis showed a poor end treatment response and SVR. On the other hand, histopathological activity was not a predictor for response to therapy. This was in accordance with Derbala et al. [17], who found no significant relation between histopathological activity and response.

Glutathione peroxidase catalyzes the reduction of hydroperoxides, including $\mathrm{H}_{2} \mathrm{O}_{2}$, by reduced $\mathrm{GSH}$ and 


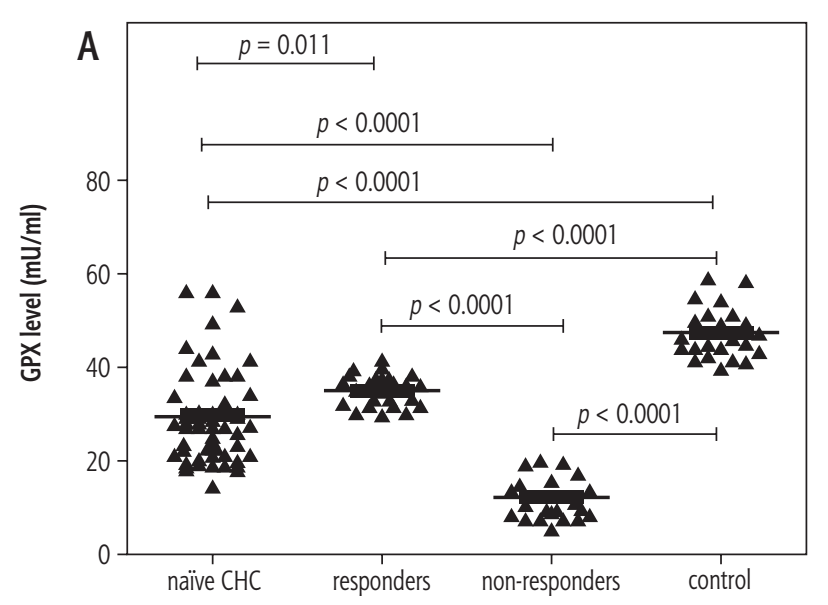

Fig. 2. Comparison between GPX and MDA levels in different groups

functions to protect the cell from oxidative damage. The enzyme uses GSH as the ultimate electron donor to regenerate the reduced form of selenocysteine [18].

Malondialdehyde is the principal and most studied product of polyunsaturated fatty acid peroxidation. This aldehyde is a highly toxic molecule and should be considered as more than just a marker of lipid peroxidation. Its interaction with DNA and proteins has often been referred to as potentially mutagenic and atherogenic [19].

The average GPX activity in erythrocytes of naïve $\mathrm{CHC}$ patients was significantly lower than its activity in the healthy controls. In addition, it was significantly higher in the responder group than the non-responder group. These findings in naive $\mathrm{CHC}$ patients and the non-responder group demonstrated that antioxidant status was compromised, with several important components of the antioxidant defense mechanism being significantly decreased.

These results agreed with Levent et al. [20], who reported that the average GPX activity in erythrocytes of patients with $\mathrm{CHC}$ before treatment was $6.52 \pm 1.86$ $\mathrm{U} / \mathrm{ml}$. It was statistically significantly lower $(p<0.05)$ than the average activity of GPX in erythrocytes of the healthy control group $(8.01 \pm 1.79 \mathrm{U} / \mathrm{ml})$. Chrobot et al. [21], studied a group of 100 individuals with $\mathrm{CHC}$. They demonstrated a GPX decrease in the blood serum of patients who were not treated with IFN. In contrast, GPX concentration was higher in the blood of patients responding to the treatment. This may be explained by the cytopathic effect of a virus causing GSH deficiency.

Contrary to GPX, plasma MDA was significantly higher in naïve $\mathrm{CHC}$ patients than in healthy controls. These results showed that the patients with $\mathrm{CHC}$ are under the influence of increased oxidative stress. Furthermore, plasma MDA concentration was significantly lower in the responder group than the non-respond-

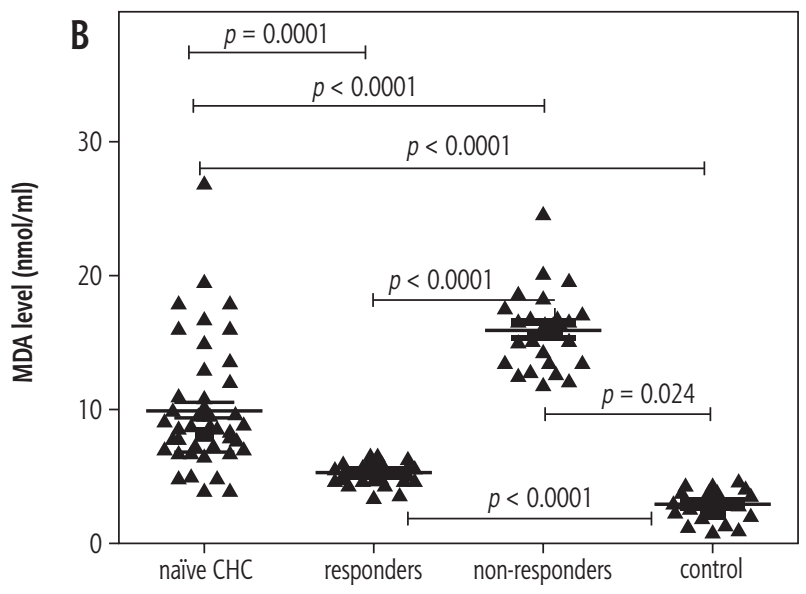

er group. Persistent HCV viremia may be responsible for the higher levels of MDA in the non-responder group. We suggest the routine use of MDA assay as an additional prognostic laboratory test for $\mathrm{CHC}$ patients.

These results agreed with Levent et al. [20], who reported that the serum MDA is significantly higher in CHC patients before treatment than in healthy subjects. Also MDA concentration decreased significantly $(p<0.001)$ after PEG-IFN- $\alpha-2 b$, and ribavirin treatment.

The negative correlation between levels of MDA and GPX in all studied groups may be explained by the fact that there is a balance between antioxidants (GPX) and oxidants (MDA) so when patients are under oxidative stress MDA increases and GPX decreases.

HCV causes severe antioxidant depletion and elevated levels of peroxidation products secondarily affect immune cells. The increased generation of reactive oxygen and nitrogen species, together with the decreased antioxidant defense, promotes the development and progression of hepatic and extrahepatic complications of HCV infection [6].

\section{Conclusions}

Lower pretreatment levels of GPX and a higher MDA level might be markers of oxidative stress occurring in HCV patients. Reversal of these levels with completion of the treatment may indicate a correlation between the oxidative stress and the viral pathogenesis. Hence antioxidant supplement can be added as a mandatory treatment in CHC patients to improve their response to antiviral treatment. However, further investigations to highlight this issue are recommended.

\section{Disclosure}

Authors report no conflict of interest. 


\section{References}

1. Ibrahim M, Gomaa W, Ibrahim Y, et al. Nitric oxide levels and sustained virological response to pegylated-interferon alpha2a plus ribavirin in chronic HCV genotype 4 hepatitis: A prospective study. J Gastrointestin Liver Dis 2010; 19: 387-392.

2. U.S. Department of Health and Human Services Food and Drug administration Center for Drug Evaluation and Research. Chronic hepatitis $\mathrm{C}$ virus infection: developing direct-acting antiviral drugs for treatment guidance for industry. 2017. https:// www.fda.gov/downloads/drugs/\%E2\%80\%A6/ucm225333.pdf

3. Benette J. Pediatric hepatitis C. http://emedicine.medscape. com/article/964761-overview2012

4. Levent G, Ali A, Ahmet A, et al. Oxidative stress and antioxidant defense in patients with chronic hepatitis $\mathrm{C}$ patients before and after pegylated interferon alfa-2b plus ribavirin therapy. J Transl Med 2006; 4: 25.

5. Aksoy H, Koruk M, Akcay F. The relationship between serum malondialdehyde and ceruloplasmin in chronic liver disease. Turkish J Biochem 2003; 28: 32-34.

6. Esrefoglu M. Oxidative stress and benefits of antioxidant agents in acute and chronic hepatitis. Hepat Mon 2012; 12: 160-167.

7. De Maria N, Colantoni A, Fagiuoli S, et al. Association between reactive oxygen species and disease activity in chronic hepatitis C. Free Radic Biol Med 1996; 21: 291-295.

8. Horsti J. Preanalytical aspects of routine coagulation measurements. Scand J Clin Lab Invest 2001; 61: 167-168.

9. Ishak K, Baptista A, Bianchi L, et al. Histological grading and staging of chronic hepatitis. J Hepatol 1995; 22: 696-699.

10. Esmat G, Metwally M, Zalata KR, et al. Evaluation of serum biomarkers of fibrosis and injury in Egyptian patients with chronic hepatitis C. J Hepatol 2007; 46: 620-627.

11. Esterbauer H, Cheeseman KH. Determination of aldehydic lipid peroxidation products: malonaldehyde and 4-hydroxynonenal. Methods Enzymol 1990; 186: 407-421.

12. Paglia DE, Valentine WN. Studies on the quantitative and qualitative characterization of erythrocyte glutathione peroxidase. J Lab Clin Med 1967; 70: 158-169.

13. Keyvani H, Fazlalipour M, Monavari SHR, Mollaie HR. Hepatitis $\mathrm{C}$ virus-proteins, diagnosis, treatment and new approaches for vaccine development. Asian Pac J Cancer Prev 2012; 13: 5917-5935.

14. Danish FA, Koul SS, Subhani FR, et al. Managing HCV infection in pediatric age group: suggested recommendations. Saudi J Gastroenterol 2010; 16: 230-235.

15. Barakat SH, El-Bashir N. Hepatitis C virus infection among healthy Egyptian children: prevalence and risk factors. J Viral Hepat 2011; 18: 779-784.

16. El-Zayadi AR. Hepatitis C comorbidities affecting the course and response to therapy. World J Gastroenterol 2009; 15: 4993 4999.

17. Derbala M, Amer A, Bener A, et al. Pegylated interferon-alpha 2b-ribavirin combination in Egyptian patients with genotype 4 chronic hepatitis. J Viral Hepat 2005; 12: 380-385.

18. Ismail NA, Okasha SH, Dhawan A, et al. Glutathione peroxidase, superoxide dismutase and catalase activities in children with chronic hepatitis. Adv Biosci Biotech 2012; 3: 972.

19. Del Rio D, Stewart AJ, Pellegrini N. A review of recent studies on malondialdehyde as toxic molecule and biological marker of oxidative stress. Nutr Metab Cardiovasc Dis 2005; 15 : 316-328.

20. Levent G, Ali A, Ahmet A, et al. Oxidative stress and antioxidant defense in patients with chronic hepatitis $\mathrm{C}$ patients before and after pegylated interferon alfa-2b plus ribavirin therapy. J Transl Med 2006; 4: 25-31.

21. Chrobot AM, Szaflarska-Szczepanik A, Drewa G. Antioxidant defense in children with chronic viral hepatitis B and C. Med Sci Monit 2000; 6: 713-718. 